\title{
ANALISIS BIAYA MINIMAL PENGGUNAAN ANTIHIPERTENSI DI RUMAH SAKIT UMUM DAERAH KOTA BONTANG
}

\author{
Mulia Indah Kusuma Dewi ${ }^{1, \dagger}$, Wisnu Cahyo Prabowo ${ }^{1}$, Rolan Rusli ${ }^{1,2, \sharp}$ \\ ${ }^{1}$ Laboratorium Penelitian dan Pengembangan Kefarmasian "Farmaka Tropis", \\ Fakultas Farmasi Universitas Mulawarman, Samarinda, Indonesia \\ †Email : kdmuliaindah@gmail.com \\ ${ }^{2}$ Kelompok Bidang Ilmu Kimia Farmasi, Fakultas Farmasi, \\ Universitas Mulawarman, Samarinda, Indonesia \\ †Email: rolan@farmasi.unmul.ac.id
}

\begin{abstract}
ABSTRAK
Hipertensi adalah suatu keadaan meningkatnya tekanan darah sistolik lebih dari 140 $\mathrm{mmHg}$ dan diastolik lebih dari $90 \mathrm{mmHg}$. Terapi utama hipertensi adalah penggunaan antihipertensi, yang membutuhkan perawatan yang lama bahkan sampai seumur hidup. Sehingga diperlukan obat-obat yang lebih ekonomis dan efektif dalam pengobatan hipertensi dalam bentuk CMA (Cost-Minimization Analysis). Penelitian ini dilakukan dengan melakukan penelusuran data secara retrospektif terhadap catatan rekam medis pasien. Hasil penelitian menunjukkan bahwa dari 38 pasien terdapat 18 pasien $(47 \%)$ adalah laki-laki dan 20 pasien (53\%) adalah perempuan. Rata-rata usia pasien terbanyak antara 51 sampai 60 tahun, dengan lama rawat inap terbanyak yaitu 1 sampai 5 hari. Obat antihipertensi yang paling banyak digunakan yaitu kombinsi 2 obat yaitu amlodipine $5 \mathrm{mg}$ dengan captopril $12,5 \mathrm{mg}$ dan amlodipine $10 \mathrm{mg}$ dengan captopril $25 \mathrm{mg}$. Berdasarkan hasil penelitian dapat disimpulkan bahwa antihipertensi yang memiliki biaya minimal adalah Rp498.800,00.
\end{abstract}

Kata Kunci: Hipertensi; Cost Minimization Analysis; Amlodipin; captopril.

DOI: https://doi.org/10.25026/mpc.v9i1.338

\section{PENDAHULUAN}

Hipertensi atau tekanan darah tinggi merupakan salah satu penyakit degeneratif yang membutuhkan perawatan yang lama bahkan sampai seumur hidup. Di Indonesia, angka kejadian hipertensi berkisar 6-15\% dari 240.000.000 jiwa penduduk Indonesia dan masih banyak penderita yang belum terjangkau oleh pelayanan kesehatan, terutama di daerah pedesaan [1].
Hipertensi merupakan salah satu faktor utama resiko kematian karena gangguan kardiovaskuler yang mengakibatkan $20-50 \%$ dari seluruh kematian. Penyebab hipertensi ini multifaktor, terdiri dari faktor genetik dan lingkungan. Dari sekian banyak penderita hipertensi, hanya sekitar $48 \%$ yang melakukan long life control terhadap penyakit ini. Hal ini tergantung pada bermacam-macam faktor, antara lain pengertian dan kesediaan penderita untuk 
berobat, faktor-faktor sosioekonomik, dan sebagainya [2].

Berdasarkan data tersebut maka pemberian terapi pengobatan yang digunakan oleh pasien tentu akan berdampak pada besarnya biaya pengobatan yang harus dikeluarkan oleh pasien. Mengingat terapi hipertensi merupakan terapi yang membutuhkan waktu lama, bahkan susah dan mahal, maka diperlukan penelitian lebih lanjut untuk mengetahui efektivitas biaya yang dikeluarkan pasien dan perbaikan kualitas hidup pasien khususnya untuk terapi antihipertensi [1].

Salah satu metodologi yang dapat digunakan untuk melakukan penelitian farmakoekomoni adalah analisis efektivitas biaya. Secara umum analisis efektivitas biaya didefinisikan sebagai tatacara analitis dan matematis yang digunakan untuk membantu dalam memilih suatu tindakan yang akan dilakukan dari berbagai alternatif pendekatan yang ada. Analisis ini telah diterapkan dalam masalah kesehatan dengan program pengobatan yang ada dapat dengan mudah diukur dalam dollar atau uang, tetapi keluaran yang diharapkan nantinya adalah peningkatan kesehatan pasien. Informasi ini dapat membantu menentukan perlakuan klinik dalam memilih pengobatan dengan efektivitas biaya terbaik [3].

\section{PROSEDUR PENELITIAN}

Penelitian ini dilakukan secara retroprospektif dengan mengambil data dari rekam medik pasien rawat inap di RSUD Kota Bontang pada periode Januari hingga Juni 2018. Teknik pengambilan sampel yang digunakan yaitu total sampling. Pengumpulan data dilakukan dengan melihat rekam medik Data pasien yang diambil adalah data pasien dengan data catatan medis yang lengkap dan keluar rumah sakit dalam keadaan cukup baik dan sehat. Data yang ada kemudian dianalisis menggunakan metode Cost Minimalization Anaysis.

\section{HASIL DAN PEMBAHASAN}

\section{Distribusi karakteristik pasien}

Distribusi penyebaran penyakit hipertensi di Rumah Sakit Umum Daerah Kota Bontang pada tahun 2018, diperoleh jumlah pasien hipertensi sebanyak 36 pasien. Dimana berdasarkan Tabel 1 dapat dilihat gambaran karakteristik pasien hipertensi yng meliputi jenis kelamin, usia, lama rawat inap. Karakteristik pasien berdasarkan jenis kelamin terdiri dari 16 (44\%) pasien lakilaki dan $20(56 \%)$ pasien perempuan. Persentase hipertensi lebih tinggi pada pasien perempuan dikarenakan setelah perempuan mengalami menopouse maka terjadi ketidakseimbangan produksi hormone. Dimana perempuan yang belum menopouse dilindungi oleh hormon estrogen yang berperan dalam meningkatkan kadar High Density Lipoprotein (HDL). Kadar kolesterol HDL rendah dan tingginya kolesterol LDL (Low Density Lipoprotein) mempengaruhi terjadinya proses aterosklerosis sehingga mengakibatkan tekanan darah tinggi [4].

$$
\text { Pasien dikelompokkan }
$$

berdasarkan usia untuk mengetahui pada rentang usia berapa pasien mengalami peningkatan tekanan darah. Dari hasil pengelompokkan data tersebut dapat diketahui bahwa hipertensi mengalami peningkatan pada rentang usia 51-60 tahun (33\%). Hal ini telah sesuai dengan pernyataan dari Sumiati (2018) bahwa umur merupakan salah satu faktor yang mempengaruhi tekanan darah. Semakin tua seseorang maka semakin besar resiko terserang hipertensi Hal ini terjadi karena pada usia tersebut arteri besar kehilangan kelenturannya dan menjadi kaku karena itu darah pada setiap denyut jantung dipaksa untuk melalui pembuluh darah yang sempit dan menyebabkan naiknya tekanan darah [3]. 
Tabel.1 Gambaran karakteristik pasien hipertensi

\begin{tabular}{|c|c|c|}
\hline Keterangan & Jumlah & Persentase $(\%)$ \\
\hline \multicolumn{3}{|l|}{ Jenis Kelamin } \\
\hline Laki-laki & 16 & 44 \\
\hline Perempuan & 20 & 56 \\
\hline \multicolumn{3}{|l|}{ Usia } \\
\hline 15 - 30 Tahun & 3 & 8 \\
\hline 31 - 40 Tahun & 4 & 11 \\
\hline 41 - 50 Tahun & 8 & 22 \\
\hline 51 - 60 Tahun & 12 & 33 \\
\hline 61 - 70 Tahun & 6 & 17 \\
\hline 71 - 80 Tahun & 3 & 8 \\
\hline > 80 Tahun & 2 & 6 \\
\hline \multicolumn{3}{|l|}{ Lama Rawat Inap } \\
\hline $1-5$ Hari & 23 & 61 \\
\hline 6 - 10 Hari & 13 & 34 \\
\hline $11-15$ Hari & 1 & 3 \\
\hline 22 hari & 1 & 3 \\
\hline
\end{tabular}

Pengelompokan pasien berdasarkan lama rawat inap dibagi menjadi 4 yaitu pada 1-5 hari, 6-10 hari, 11-15 hari dan 22 hari. Sehingga pada Tabel I menunjukan bahwa pasien paling banyak pada rentang 1-5 hari (61\%), pasien terbanyak kedua yaitu pada rentang 6-10 hari (34\%), yang ketiga yaitu pada rentang 11-15 hari (3\%) dan yang terakhir yaitu pada 22 hari $(3 \%)$. Hal ini dapat mempengaruhi biaya yang akan dikeluarkan oleh pasien.

\section{Gambaran penggunaan obat antihipertensi}

Penggunaan obat antihipertensi pada pasien hipertensi sangat berperan penting dalam pengaturan tekanan darah pasien. Distribusi penggunaan obat dapat dilihat pada Tabel 2, dimana obat dikelompokkan menjadi 4 kelompok yaitu antihipertensi tunggal, kombinasi 2 obat antihipertensi, kombinasi 3 obat antihipertensi dan kombinasi 4 obat antihipertensi. Pada Tabel 2 dapat diketahui bahwa obat antihipertensi yang paling banyak digunakan adalah kombinasi dua obat yaitu amlodipine 5 mg dengan captopril 12,5 mg sebanyak 4 pasien $(11 \%)$.

\section{Biaya terapi Antihipertensi}

Analisis yang digunakan untuk menentukan obat yang memiliki biaya yang paling minimal yang dikeluarkan pasien yaitu dengan metode CMA (Cost Minimization Analysis), dimana jumlah total biaya yang dikeluarkan oleh pasien dibagi dengan jumlah kasus terapi. Berdasarkan hasil dari data penggunaan obat antihipertensi yang paling banyak digunakan di Rumah Sakit Umum Daerah Kota Bontang diperoleh obat antihipertensi kombinasi antara amlodipine $10 \mathrm{mg}$ dengan captopril 25 $\mathrm{mg}$ dan amlodipine $5 \mathrm{mg}$ dengan captopril $12,5 \mathrm{mg}$. 
Tabel 2. Gambaran distribusi penggunaan ob at antihipertensi

\begin{tabular}{lccc}
\hline & Nama Obat & Jumlah & Persentase (\%) \\
\hline & Tunggal & & \\
Pr 10 mg & & 1 & 3 \\
Cs 8 mg & & 2 & 6 \\
L 5 mg & & 1 & 3 \\
\hline
\end{tabular}

\section{Kombinasi 2 obat}

A $5 \mathrm{mg}+\mathrm{Cp} 12,5 \mathrm{mg}$

A $10 \mathrm{mg}+\mathrm{Cp} 25 \mathrm{mg}$

A $10 \mathrm{mg}+\mathrm{F}$ injeksi

A $5 \mathrm{mg}+$ Cs $8 \mathrm{mg}$

A $10 \mathrm{mg}+\mathrm{Cp} 12,5 \mathrm{mg}$

$\mathrm{F}$ tab $+\mathrm{F}$ injeksi

$4 \quad 11$

Cs $8 \mathrm{mg}+\mathrm{F}$ injeksi

\section{Kombinasi 3 obat}

A $5 \mathrm{mg}+\mathrm{Cp} 12,5 \mathrm{mg}+\mathrm{Cs} 8 \mathrm{mg}$

$\mathrm{N}$ injeksi + Cs $16 \mathrm{mg}+\mathrm{A} 10 \mathrm{mg}$

F injeksi + Cs $16 \mathrm{mg}+\mathrm{A} 10 \mathrm{mg}$

Cp $25 \mathrm{mg}+\mathrm{Cp} 50 \mathrm{mg}+\mathrm{A} 10 \mathrm{mg}$

$\mathrm{Cp} 25 \mathrm{mg}+\mathrm{A} 10 \mathrm{mg}+\mathrm{A} 5 \mathrm{mg}$

A $10 \mathrm{mg}+\mathrm{Cp} 25 \mathrm{mg}+\mathrm{B} 5 \mathrm{mg}$

A $5 \mathrm{mg}+\mathrm{F}$ injeksi $+\mathrm{R} 2,5 \mathrm{mg}$

Cs $16 \mathrm{mg}+\mathrm{A} 5 \mathrm{mg}+\mathrm{F}$ injeksi

Cs $8 \mathrm{mg}+\mathrm{A} 5 \mathrm{mg}+\mathrm{F}$ injeksi

Cs $8 \mathrm{mg}+\mathrm{A} 10 \mathrm{mg}+\mathrm{F}$ injeksi

B $5 \mathrm{mg}+\mathrm{A} 10 \mathrm{mg}+\mathrm{F}$ injeksi

\section{kombinasi 4 obat}

F injeksi + L $5 \mathrm{mg}+\mathrm{L} 10 \mathrm{mg}+\mathrm{F}$ tab

Cs $16 \mathrm{mg}+\mathrm{F}$ injeksi $+\mathrm{A} 5 \mathrm{mg}+\mathrm{A} 10 \mathrm{mg}$

$\mathrm{R} 5 \mathrm{mg}+\mathrm{A} 5 \mathrm{mg}+\mathrm{F}$ injeksi $+\mathrm{F}$ tab

F injeksi + A $10 \mathrm{mg}+\mathrm{Cs} 16 \mathrm{mg}+\mathrm{B} 5 \mathrm{mg}$

Cp 12,5 mg + S $25 \mathrm{mg}+\mathrm{F}$ injeksi + A $5 \mathrm{mg}$

$\mathrm{F}$ injeksi $+\mathrm{A} 10 \mathrm{mg}+\mathrm{C} 16 \mathrm{mg}+\mathrm{F}$ tab

Cs $16 \mathrm{mg}+\mathrm{Cs} 8 \mathrm{mg}+\mathrm{F}$ tab + A $5 \mathrm{mg}$

Keterangan : $\mathrm{A}=$ Amlodipine, $\mathrm{Cp}=$ Captopril, $\mathrm{Cs}=$ Candesartan, $\mathrm{N}=$ Nicardipin, $\mathrm{F}=$ Furosemid, L= lisinopril, $\mathrm{Pr}=$ Propanolol, $\mathrm{B}=\mathrm{B}$ isoprolol, $\mathrm{R}=$ Ramipril, $\mathrm{S}=$ Spironolaktone.

Tabel. 3 Amlodipin $10 \mathrm{mg}+$ Captopril $25 \mathrm{mg}$

\begin{tabular}{|c|c|c|c|c|c|c|}
\hline \multirow[t]{2}{*}{ No. } & \multirow{2}{*}{$\begin{array}{l}\text { LOS } \\
\text { (hari) }\end{array}$} & \multicolumn{3}{|c|}{ Variable cost } & \multirow{2}{*}{$\begin{array}{c}\text { Fixed cost } \\
\text { Administrasi } \\
\text { ruangan }(\mathrm{Rp}) \\
\end{array}$} & \multirow{2}{*}{$\begin{array}{c}\text { Biaya Total } \\
\text { (Rp) }\end{array}$} \\
\hline & & $\begin{array}{c}\text { Biaya obat } \\
\text { antihipertensi (Rp) }\end{array}$ & $\begin{array}{c}\text { Biaya tindakan \& } \\
\text { perawatan }(\mathrm{Rp})\end{array}$ & $\begin{array}{c}\text { Biaya } \\
\text { Dokter(Rp) }\end{array}$ & & \\
\hline 1 & 3 & Rp28.198,00 & Rp111.828,00 & Rp50.000,00 & Rp150.000,00 & Rp340.026,00 \\
\hline 2 & 8 & Rp3.312,00 & $\mathrm{Rp} 240.000,00$ & Rp175.000,00 & Rp400.000,00 & Rp818.312,00 \\
\hline 3 & 4 & Rp10.452,00 & Rp170.000,00 & Rp150.000,00 & Rp200.000,00 & Rp530.452,00 \\
\hline \multicolumn{6}{|c|}{ CMA } & Rp562.930,00 \\
\hline
\end{tabular}


Tabel 4. Amlodipin $5 \mathrm{mg}+$ Captopril 12,5 mg

\begin{tabular}{|c|c|c|c|c|c|c|}
\hline \multirow[t]{2}{*}{ No. } & \multirow{2}{*}{$\begin{array}{l}\text { LOS } \\
\text { (hari) }\end{array}$} & \multicolumn{3}{|c|}{ Variable cost } & Fixed cost & \multirow{2}{*}{$\begin{array}{l}\text { Biaya Total } \\
\text { (Rp) }\end{array}$} \\
\hline & & $\begin{array}{c}\text { Biaya obat } \\
\text { antihipertensi (Rp) }\end{array}$ & $\begin{array}{c}\text { Biaya tindakan \& } \\
\text { perawatan }(\mathrm{Rp})\end{array}$ & $\begin{array}{l}\text { Biaya Dokter } \\
(\mathrm{Rp})\end{array}$ & $\begin{array}{l}\text { Administrasi } \\
\text { ruangan }(\mathrm{Rp})\end{array}$ & \\
\hline 1 & 5 & Rp1.713,00 & Rp420.000,00 & Rp280.000,00 & Rp100.000,00 & Rp801.713,00 \\
\hline 2 & 4 & Rp2.928,00 & Rp294.900,00 & $\mathrm{Rp} 150.000,00$ & Rp150.000,00 & Rp597.828,00 \\
\hline 3 & 1 & Rp2.196,00 & Rp110.000,00 & Rp25.000,00 & Rp150.000,00 & Rp287.196,00 \\
\hline 4 & 3 & Rp3.465,00 & Rp80.000,00 & Rp75.000,00 & Rp150.000,00 & Rp308.465,00 \\
\hline & \multicolumn{5}{|c|}{ CMA } & Rp498.800,00 \\
\hline
\end{tabular}

Berdasarkan hasil penelitian yang dapat dilihat pada Tabel 3 dan Tabel 4 dihitung rata-rata per pasien yang diperoleh dari penjumlahan biaya harga obat, biaya perawatan dan tindakan, biaya dokter, dan biaya administrasi ruangan kemudian dibagi dengan jumlah pasien sehingga diperoleh rata-rata sebesar Rp562.930,00 yang menggunakan amlodipine $10 \mathrm{mg}$ dengan captopril 25 mg sedangkan rata-rata biaya medik pada amlodipine $5 \mathrm{mg}$ dengan captopril 12,5 mg sebesar Rp498.800,00. Dilihat dari hasil yang didapat biaya yang dikeluarkan pasien yang menggunakan amlodipine $5 \mathrm{mg}$ dengan captopril 12,5 mg lebih kecil dibandingkan dengan pasien yang menggunakan amlodipine 10 mg dengan captopril $25 \mathrm{mg}$.

\section{KESIMPULAN}

Karakteristik pasien menunjukan pasien perempuan lebih banyak terkena hipertensi dibandingkan dengan pasien laki-laki. Antihipertensi yang paling banyak digunakan oleh pasien hipertensi rawat inap di Rumah Sakit Umum Daerah Kota Bontang yaitu jenis kombinasi 2 obat antihipertensi yaitu amlodipine $5 \mathrm{mg}$ dengan captopril 12,5 $\mathrm{mg}$ dan amlodipine $10 \mathrm{mg}$ dan captopril $25 \mathrm{mg}$. Dan obat antihipertensi yang memiliki biaya paling minimal yang dianalisis dengan metode CMA (Cost Minimization Analysis) yaitu amlodipin $5 \mathrm{mg}$ dengan Captopril 12,5 mg yaitu sebesar Rp 498.800,00.

\section{DAFTAR PUSTAKA}

[1] Niken, Wijayanti., et all. 2016. Analisis Efektivitas Biaya Pengobatan Kombinasi Amlodipin Furosemid Dibandingkn Dengan Kombinasi Amlodipin Bisoprolol Pada Pasien Hipertensi Rawat Jalan di RSUD Undata Palu Peroide Agustus-Oktober Tahun 2014. Jurnal Of Natural Science Volume 5 Nomor 1: $101-110$

[2] Andayani, Tri Murti. 2006. Efektivitas Biaya Penggunaan ACEInhibitor vs Calcium Chanel Bloker Pada Pasien Hipertensi dengan Diabetes Melitus. Laporan Hasil Penelitian Fakultas Farmasi UGM

[3] Lilis, Sumiati., et all. 2018. Analisis Efektivitas Biaya Terapi Antihipertensi Pada Pasien Hipertensi Rawat Inap Di RSU Pancaran Kasih GMIM Manado. Pharmacon Jurnal Ilmiah FarmasiUNSRAT Volume 7 Nomor 1

[4] Anggraini, AD., Waren, S., Situmorang, E., Asputra, H., dan Siahaan, SS. 2009. Faktor--Faktor Yang Berhubungan Dengan Kejadian Hipertensi Pada Pasien Yang Berobat Di Poliklinik Dewasa Puskesmas Bangkinang Periode Januari Sampai Juni 2008.Fakultas Kesehatan. Universitas Riau. Files of DrsMedFK UNRI : $1-41$ 